\title{
Entre nostalgia e modernidade: eclético e Déco no Brasil
}

\author{
José Carlos Magro Junior, \\ Paula da Cruz Landim*
}

\begin{abstract}
Resumo O eclético e o Art Déco foram dois estilos presentes na constelação arquitetônica do mundo no século XIX e XX. Sob a ótica dos fenômenos, dentro do território brasileiro, procura-se estabelecer relações a partir da configuração do espaço e sua relação social, cultural e política. Ambos os movimentos tiveram um impacto significativo na paisagem brasileira e suas relações de influência apresentam raízes mais profundas. Neste trabalho o objetivo foi abordar qual a relação e quais as circunstâncias que possibilitaram o redesenho arquitetônico brasileiro pelas novas práticas decorativas que emergiam. A partir dessa análise buscamos conectar a linguagem da arquitetura a caminhos que levaram o país rumo à modernização.
\end{abstract}

Palavras-chave: arquitetura, art déco, ecletismo.

\section{Entre nostalgia y modernidad: ecléctico y Déco en Brasil}

Resumen El eclecticismo y el Art Deco fueron dos estilos presentes en la constelación arquitectónica del mundo en los siglos XIX y XX, desde la perspectiva de los fenómenos dentro del territorio brasileño buscamos establecer relaciones desde la configuración del espacio y su relación social, cultural y política. Ambos movimientos tuvieron un impacto significativo en el paisaje brasileño y sus relaciones de influencia tienen raíces más profundas. En este trabajo, el objetivo era abordar la relación y las circunstancias que hicieron posible el rediseño arquitectónico brasileño debido a las nuevas prácticas decorativas que surgieron. Con base en este análisis, buscamos conectar el lenguaje de la arquitectura a los caminos que llevaron al país hacia la modernización.

Palabras clave: arquitectura, art déco, eclecticismo.

\section{Between nostalgia and modernity: eclectic and Déco in Brazil}

\begin{abstract}
Eclecticism and Art Deco were two styles present in the architectural constellation of the world in the nineteenth and twentieth centuries, from the perspective of the phenomena within the Brazilian territory we seek to establish relationships from the configuration of space and its social, cultural and political relationship. Both movements had a significant impact on the Brazilian landscape and their relations of influence have deeper roots. In this work, the objective was to address the relationship and the circumstances that made the Brazilian architectural redesign possible due to the new decorative practices that emerged. Based on this analysis, we seek to connect the language of architecture to paths that led the country towards modernization.
\end{abstract}

Keywords: architecture, art déco, eclecticism. 
A

transformação social e cultural refletida por meio da linguagem arquitetônica é o que motiva a pesquisa desenvolvida neste trabalho. Por meio da análise crítica e reflexão são direcionados caminhos para relações que incluem a transformação da sociedade frente à modernidade e, como a configuração das habitações, refletem não só o interior das residências, mas o interior de uma nação.

O ecletismo configura-se como um estilo projetual que descende das Revoluções ocasionadas durante o século XVIII e XIX na Europa. Posteriormente, este estilo se espalhou por todos os lados do mundo, no reflexo de uma sociedade pautada na imagem, simulacro ${ }^{1}$ e ascensão social. Outro fator que permitiu a emergência deste estilo foi a sua relação com a burguesia industrial, classe social que ascende socialmente com os adventos da Revolução Industrial.

A Revolução Industrial foi um conjunto de transformações relacionadas à alteração das formas de planejamento, produção e distribuição, em especial, de produtos feitos em grande escala. No centro do movimento, a máquina a vapor e a produção de materiais têxteis, abrem espaço para novas formas decorativas, desenvolvimento e ampliação das práticas de projeto (DENIS, 2008). Com a transformação sociocultural a Revolução Industrial encarna no setor produtivo a capacidade da criação de novas formas para produtos que serão consumidos pela população. A sociedade de massa, que emerge na Europa no período, busca uma alteração das práticas de consumo, influenciando em uma reforma do gosto.

O consumo na Era Vitoriana era o espetáculo. O fascínio do século XIX com as aparências faz com que as áreas projetuais se desenvolvam à imagem de seus subsidiários. E como fica marcado pelas épocas anteriores, a construção de palácios no período monárquico recente e, a opulência da manifestação expressa no lar, encontra nesse novo sentido social uma forma de definir e legitimar seu espaço (DENIS, 2008).

* José Carlos Magro Junior é graduado em Design, graduado em Design, Mestrando no Programa de Pós-Graduação em Design (PPG Design) da Faculdade de Arquitetura, Artes e Comunicação (FAAC/UNESP/Bauru), ORCID <https://orcid.org/00000002-2568-2277>. Paula da Cruz Landim é Arquiteta e Urbanista, professora do Departamento de Design da Faculdade de Arquitetura, Artes e Comunicação - FAAC da Universidade Estadual Paulista, UNESP - campus de Bauru, ORCID <https://orcid. org/0000-0002-1510-7738>.
No Brasil, a história de dependência que durou centenas de anos só se confirma. O estilo eclético é adotado fortemente na paisagem urbana brasileira. O estilo se difunde país adentro junto das inúmeras missões que tinham interesse no desbravamento deste interior tropical. Ao longo desta pesquisa serão mostrados como as relações entre cultura, sociedade, política e economia estabelecem laços e servem de força transformadora para um povo a partir da análise de sua produção material.

Na virada do século XX um novo estilo aparece no canteiro de obras e faz o desejo da mesma burguesia que quis o eclético querer o Art Déco. Coexistindo, as expressões aplicadas à arquitetura transformam o país colonial em um país que busca sua modernização. Uma soma de desejos utópicos encarna na sociedade industrial brasileira, que se molda às tentativas de parecer grande. Ao longo deste trabalho evidenciamos o objetivo de refletir sobre uma sociedade pautada nas áreas e nas interações entre elas, a fim de conseguir um panorama mais claro e interpretativo sobre o que aconteceu na 
1 Para o autor, nessa passagem para um espaço que já não é o real, a era da simulação iniciase com a liquidez de todos os referenciais - pela ressureição artificial nos sistemas de signos. BAUDRILLARD, Jean. Simulacros e simulação. Lisboa: Relógio d'Água, 1991. história e aqui é questionado: qual a relação do eclético e do Art Déco na arquitetura brasileira e na formação deste país?

A hipótese é que ambos estilos foram forças propulsoras na reforma e na implementação da arquitetura moderna no país. Para tal utilizamos o método de pesquisa bibliográfica, de natureza qualitativa, com intenção de desenvolvimento teórico a respeito do objetivo elencado. A revisão da literatura fornecerá subsídios para análise, sobretudo pelo panorama histórico, na junção dos itens abordados. Pretende-se fazer uma leitura crítica e reflexiva sobre o estilo eclético e Art Déco na arquitetura brasileira.

\section{Fundamentação teórica}

\section{O estilo eclético no século XVIII e XIX}

Com a falência das antigas tradições, especialmente o Humanismo que dominava o continente europeu desde o Renascimento, e nesse período de novas aberturas surge no horizonte urbano um novo tipo de configuração do lar que, pela visão interna e externa, simboliza condições econômicas de uma burguesia em ascensão preocupada com as aparências e suas constituições.

Para Bonametti (2007), relacionado ao pensamento sociológico, surge o conceito de modernização, que descreve os processos de transformação de uma sociedade moderna que se industrializou à forma das sociedades ocidentais. O surgimento do capitalismo na Europa Ocidental e América do Norte se torna modelo a ser seguido para as demais. O caos urbano proveniente da nova sociedade industrial, influenciado pela luta de classes e abalado pelas carências estruturais cria na nova cidade industrial problemas que são contraditórios em si mesmos. Os arquitetos do século XIX começaram a projetar edifícios em diversos estilos, e essa arquitetura é definida como eclética. Sendo o ecletismo um substantivo que significa a atitude antiga de formar um todo, a partir de elementos escolhidos em diferentes sistemas.

O ecletismo encontra seu argumento no embate causado pela Revolução Industrial nas novas formas de concepção de produtos oriundos do trabalho mecanizado. Nesse cenário emerge uma nova classe social, a burguesia industrial do século XIX, que encontra na Revolução uma forma de ascensão social. Marcada pela busca de status e, no crescente sentimento de individualismo, junto da nostalgia dos grandes feitos e heróis nacionais colocadas em questão pelo Romantismo, o burguês vitoriano encontra no ecletismo um estilo encomendado, despido de qualquer sinal de cultura aristocrática, característica do século anterior (FABRIS, 1993).

Como analisa Denis (2008), nas grandes concentrações urbanas que se estabeleciam ao longo do século XIX, a preocupação com a aparência atingiu seu auge, o anonimato na metrópole, a desconfiança sobre a vizinhança e o novo ritmo de vida fez com que a importância dada ao exterior das casas passasse a ditar o sentido interior da residência, passível de apresentação e identificação.

Patetta (1987) observa que a produção industrial, encarada como simples curiosidade intelectual no século XVIII, explode no século XIX impondo suas leis econômicas também ao canteiro de obras. E Pevsner (1970, p. 200) acrescenta que: 
A incultura e o individualismo são características do novo rico vitoriano. Se, por uma razão qualquer, um diretor de fábrica tiver-se apegado a um estilo, nada o impedirá de mandar construir sua casa, seu ateliê, seu escritório, seu clube, naquele estilo [...] os amadores do século XVIII tinham explorado tantas formas fantasiosas, proposto tantos estilos, os poetas românticos se compraziam com tantos sonhos nostálgicos do longínquo no tempo e no espaço que os novos mecenas só tinham dúvida da escolha.

O autor apresenta argumentos de que o século XVIII tem uma matriz eclética. A postura investigativa do lluminismo, sua concepção de conquista aplicada à cultura e sua constante necessidade de revisão dos estilos, inclusive o Clássico, dão à luz do presente uma oportunidade de viabilizar esse desejo, que será característica do próximo século (PEVSNER, 1970).

Isso nos leva a interpretar o período que vai da metade do século XVIII até o início do século XX como um longo período, caracterizado por intensas manifestações que ocorrem nesse recorte temporal. Reencontra-se uma continuidade histórica que tem origem na crise da antiga tradição clássica e vitoriana, que resulta no abandono total de qualquer referência aos estilos históricos, pretendido pela arte moderna.

A essas exigências tão concretas e tão decisivas para a nova edificação, os arquitetos deram a única resposta possivel: uma arquitetura sem grandes tensões espirituais, não autônoma, mas participante e comprometida até o próprio sacrifício. A cultura arquitetônica deleitou-se, por mais de cem anos, com o fato de ter acolhido os mais variados elementos lexicais, extraindo-os de todas as épocas e regiões, recompondo-os de diferentes maneiras, de acordo com princípios ideológicos [...]. (PATETTA, 1987, p.14)

Para Fabris (1993) não se pode negligenciar a influência causada pelos novos meios de difusão de informação e de conhecimentos do homem oitocentista. Sem se preocupar com este ou aquele estilo, o indivíduo do século XIX transita livremente entre o passado e o presente, aberto a tudo o que acontece, sem se firmar a um momento histórico. A veiculação da mídia impressa como jornais, revistas, catálogos, manuais, enciclopédias, etc., além do crescente número de imagens veiculadas através de gravuras e fotografias, colocam esse indivíduo no interior de uma complexa rede de relações e informações. Argan (1974) coloca que a volta ao passado não se trata de uma questão filológica, pelo estudo da linguagem por fontes históricas, mas sim por uma questão que se ditada pelos ciclos de modismos, pelo padrão de consumo da nova sociedade industrial burguesa, cuja estética e materiais são integrados à um conjunto arquitetônico fantasioso.

O estético não é cognitivo, mas ele tem alho da forma e da estrutura do racional; e ele assim nos une com toda a autoridade da lei, mas num nivel mais afetivo e intuitivo. $O$ que nos reúne enquanto sujeitos não é o conhecimento, porém uma inefável reciprocidade de sentimentos. E esta é certamente uma razão importante pela qual a estética ocupa um lugar tão central no pensamento burguês. (EAGLETON, 1993, p. 59)

A partir dos estudos do século XIX fica evidente que os arquitetos deveriam ter uma competência no campo tecnológico, mas também uma especificidade necessária para 
estudos sobre escultura e pintura, iniciando uma atenção à decoração e ao ambiente. Grande parte desses estudos, estavam ligados direta ou indiretamente, aos problemas da restauração. Assim, o ecletismo deu à problemática da restauração uma posição processual, aberta e dialética, de caráter altamente moderno (PATETTA, 1987).

Já Mignot (1983) diz o oposto, o movimento "duplamente retrospectivo e prospectivo" (p. 309), que passa aos arquitetos pelo uso e experimentação de novos materiais e novos modelos dentro da sociedade industrial e, ao descobrirem valores que são colocados em voga pelo Romantismo, incluem esse movimento adaptado às exigências contemporâneas. O caráter plural do estilo eclético denota não somente um fator artístico, mas uma nova forma de organização da sociedade e cultura que coloca fim a qualquer tentativa de unidade ao direcionar ao múltiplo e ao diversificado.

Para Patetta (1987) o ecletismo era a cultura arquitetônica própria de uma classe burguesa, que preferia o conforto e amava o progresso. Entusiasmados pelas novidades e pela melhoria da própria qualidade de vida, rebaixava a produção arquitetônica artística ao nível da moda e do gosto. Porém a arquitetura do século XIX traz em si uma ideia dominante de representação. O que a forma exterior evidencia é o status de seu ocupante, seja o Estado, seja o indivíduo. Devido a isso que a decoração se torna um elemento indispensável a ser usada em larga escala, onde se multiplica a função ilusória dos materiais e acabamentos, onde o erudito e o pitoresco se misturam.

Portanto, podemos considerar decisórios os fatores estruturais de todo o período, isto é, a consolidação do poder burguês, os rumos tomados pela sociedade industrial e a ligação com a cultura romântica - dos ideais nacionais e de independência da produção em série, a expansão do mercado consumidor e a importância da estética dentro do pensamento da burguesia europeia. A razão pela ascensão do estilo eclético também se deve ao grande número de profissionais autodidatas que colocam o debate prático da arquitetura para longe da academia. Essa ampliação explica a multiplicidade presente no ecletismo.

Deste capítulo pode-se perceber que a questão eclética não é um fator que interessa apenas à arquitetura. O ecletismo se apresenta como um fenômeno vasto que necessita de uma abordagem contextualizada, interdisciplinar, para o cruzamento de informações não vistas a um estudo do movimento isolado, mas a uma expressividade que está ligada diretamente a todo período de transformações sociais, econômicas, culturais, ideológicas e políticas.

\section{Ecletismo para formação da identidade nacional}

Se para o povo europeu o ecletismo é o estilo da modernidade que lida naturalmente com os problemas do passado, para o povo brasileiro a situação é outra. O passado para o qual os arquitetos brasileiros se voltam não é nacional, a afirmação eclética no Brasil não significa que os valores inspirados para tal manifestação são da tradição interior, e sim uma total negação aos vestígios coloniais que perseguiram o Brasil em sua história (FABRIS, 1993).

Salgueiro (1986) define o imigrante como papel fundamental para a definição do perfil da arquitetura brasileira no fim do século XIX, que carregados de outros valores 
2 CARDOSO, F. H. As idéias e seu lugar. Rio de Janeiro: Paz e Terra, 1980. culturais e costumes, impõe aos brasileiros o seu ambiente. O movimento migratório do Brasil no século XIX impulsionou a presença dos estrangeiros neste admirável novo mundo. Diante desse cenário de constantes alterações e aperfeiçoamentos duas alternativas estavam presentes, ora pelos arquitetos, engenheiros e mestres de obras com formação acadêmica ou profissional através de possibilidades do próprio país, ora essa mão de obra vinha diretamente de fora do país.

O crescimento das populações urbanas forçou o convívio e a tolerância com o outro, as cidades não tinham só mais gente, mas, sobretudo, gente de diferentes culturas. E o Brasil, colonizado durante trezentos anos, tornava-se um lugar de convivência, mestiçagem e sincretismo. No mesmo espaço coexistiam alemães, italianos, sírios, povos africanos, indígenas, etc.; e a dinâmica da vida na cidade forçava a convivência dos estilos, funções e identidades, o que reflete na pluralidade cultural e arquitetônica pelo acúmulo de camadas históricas (BONAMETTI, 2007).

Nas cidades brasileiras, a modernização já era percebida a partir do século XIX, através da expansão ferroviária, uso do telégrafo, do motor de explosão, além das intervenções urbanas. Já as três primeiras décadas do século XX foram ricas em propostas de melhorias para as cidades, com prioridade as obras de infraestrutura como saneamento, regulação do sistema viário, além dos projetos para áreas centrais (LEME, 1999).

Bruand (1981) considera a arquitetura brasileira no início do século XX como sem originalidade. Interessada na mimese de obras de maior prestígio ou em copias da moda europeia, apresentam o que é produzido no Brasil como um complexo de inferioridade. E o complexo de inferioridade implica na validação da teoria da dependência ${ }^{2}$, o desejo brasileiro de ser estrangeiro, o desejo em ser uma sede cosmopolita, que toma conta do país após a proclamação da República sob o lema do progresso, indústria, capital e modernização.

A modernização brasileira se caracteriza como um atraso cultural com a inserção tardia dos brasileiros no mundo moderno, sempre em dependência de culturas exteriores ao território. A centralização da influência cultural na França e Inglaterra transformou o eclético brasileiro, principalmente das elites, em cópia dos padrões europeus com poucas adaptações ao cenário nacional. A crescente valorização do contato com a natureza descende do processo de industrialização na Europa (BONAMETTI, 2007).

Queiroz (1981) completa que a modernidade imposta ao Brasil na virada do século não representa um caráter compensatório pois, a problemática é bem mais complexa. Quando se discute sobre importação cultural, não basta somente notar o fenômeno, mas sim, suas relações que implementam tal fenômeno, assim como suas adoções, elementos e resultados finais.

A ideologia da Belle Époque, compreendida por Fabris (1993), atenta sobretudo sobre a criação de um cenário teatralizado no qual o produto cultural é símbolo de função e ornamentação, desempenhando um papel de maquiagem, cujos anseios correspondem à arquitetura de importação, e completa:

País mestiço que sonha branco, país que começa a experimentar o processo industrial e já se crê plenamente moderno, o Brasil de fins do século XIX deseja romper de 
Figura 1: Viaduto Santa Efigênia, ao fundo o Mosteiro de São Bento. Fonte: http://bit.ly/37Yzf9z. vez com o estatuto colonial, projetando-se integralmente num modelo econômico e cultural que lhe permitiria superar de imediato um passado com o qual não se identificava e que procura apagar, sem rodeios, como comprova a remodelação do Rio de Janeiro quando da construção da Avenida Central. (FABRIS, 1993, p. 136)

Caracteriza o final do século XIX denominado Belle Époque, pela crença que o progresso material seria responsável por resolver tecnicamente os problemas da humanidade. 0 paradigma de modernização foi o de Paris, através da reforma urbana do barão GeorgesEugène Haussmann, entre 1853-1869. Influenciado pelas ações do período, o então prefeito do Rio de Janeiro, Francisco Pereira Passos, propôs um conjunto de medidas sanitárias que resultaram em mudanças drásticas e transformações paisagísticas e urbanísticas, incluindo a mudança da planta da cidade, ações de vigilância sanitária, alargamento de avenidas, e essas atitudes ficaram conhecidas como operação 'bota-abaixo' (BONAMETTI, 2007).

Na cidade de São Paulo, capital paulista, a intervenção aconteceu no Vale do Anhangabaú, no Parque Trianon e na Avenida Paulista (figuras 1 e 2). Foi o capital vindo da indústria do café que permitiu e subsidiou a reformas urbanas na cidade. $\mathrm{E}$ Moraes (1998, p. 34-35) acrescenta que:

Por tudo isso, por volta de 1905-07 a indústria em São Paulo ganhou um grande impulso, mas [...], ainda representava somente 16,5\% da produção industrial. Crescendo incessantemente na década de 1910, esse vertiginoso processo de desenvolvimento se revelaria de maneira candente nos anos de 1920. A população paulistana, por exemplo, aumentou tremendamente, tornando São Paulo a segunda cidade do país e a de maior taxa de crescimento entre todas as cidades brasileiras.

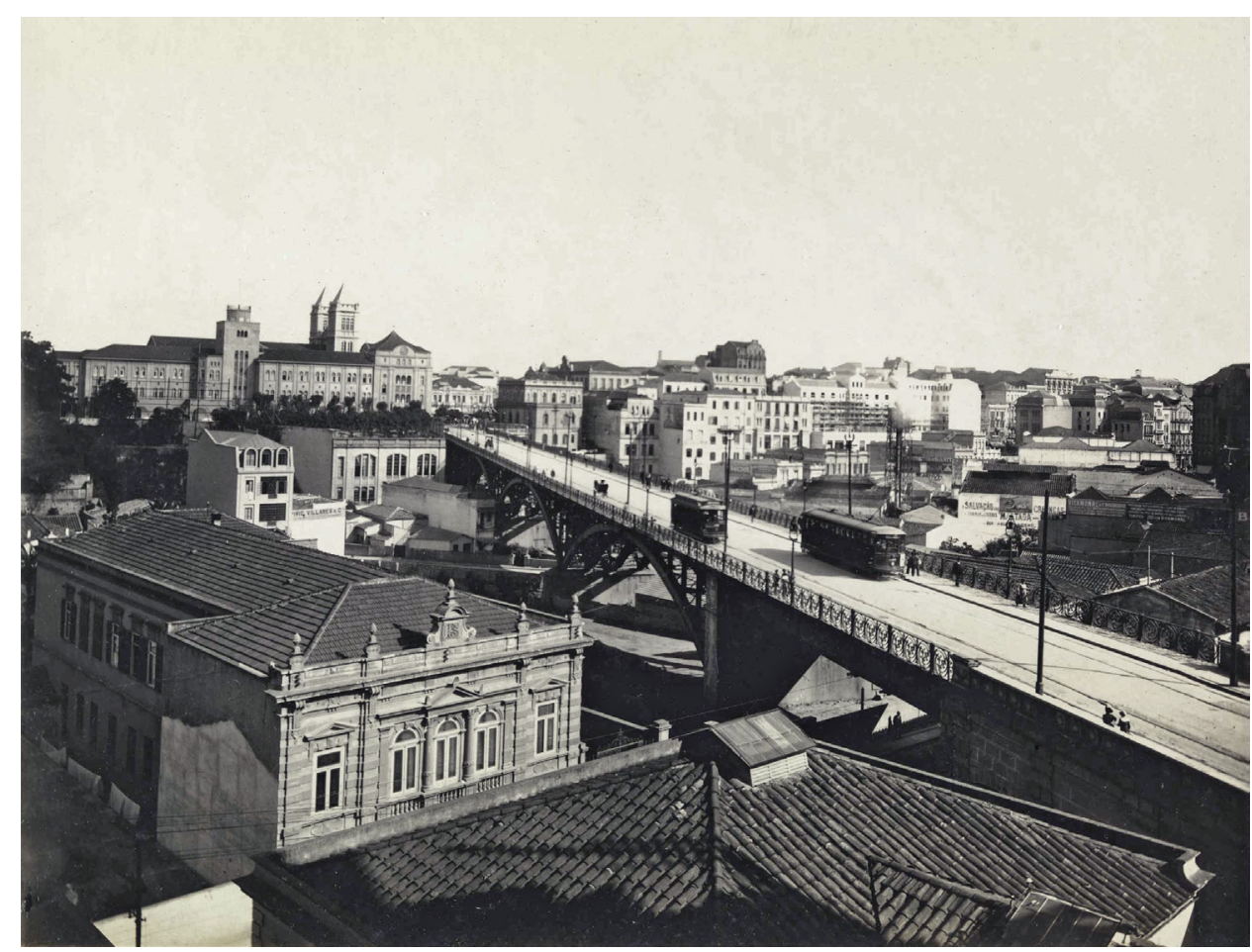


Figura 2: Avenida Paulista e seus casarões. Fonte: https://bit. ly/37WFoCV.

3 RUSKIN, John. As pedras de Veneza. São Paulo: Martins Fontes, 1992.

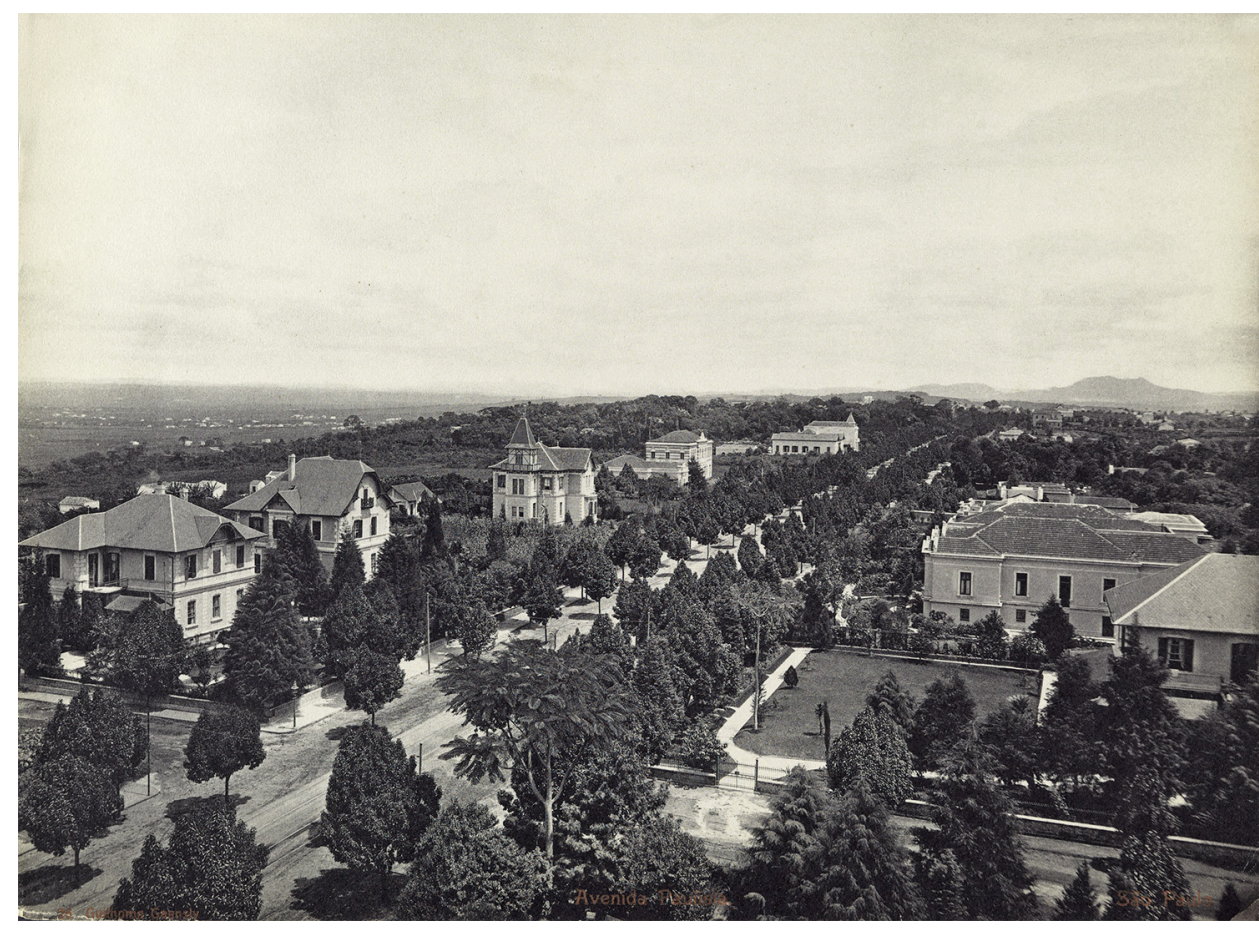

Moraes (1998) apresenta que o bairro Jardim América, considerado um dos melhores bairros da cidade, foi implantado a partir da primeira década do século XX seguindo o padrão de Ebenezer Howard - Cidade Jardim - reforçando os modelos modernos da civilização europeia. No que afeta o restante da cidade, em 1930, sob a gestão de Francisco Prestes Maia, surge o Plano de Avenidas, como um exemplo da nova forma de planejamento urbano. Propondo um sistema articulado de vias radiais e perimetrais, o plano propôs uma nova forma de circulação entre bairros e centro.

A vontade de ser moderno faz a arquitetura brasileira tolerar os produtos de uma indústria, que na Europa, eram mais disfarçados para não mostrarem o mau gosto da arquitetura representativa. É o exemplo dos produtos de ferro, adotados pelo ecletismo, e que no Brasil tiveram uma acolhida tão positiva que os resquícios estão até hoje no interior do país. Se na Europa, o ferro era disfarçado de material nobre, gerando os protestos de Ruskin ${ }^{3}$, no Brasil, existem casos de coluna de madeira que fingem ser de ferro. Uma modernidade meramente simbólica.

As novas formas de divulgação, o surgimento da sociedade de massa e a expansão do liberalismo impõem à arquitetura outras funções que não as tradicionais. Assim, uma mesma concepção de status informava todas as classes sociais e não somente a elite. Tanto nos bairros de classe média ou nos bairros populares, surgem construções estruturalmente simples, mas cheias de detalhes decorativos que simbolizavam as aspirações sociais de seus moradores. As fachadas estilísticas das ruas se anulavam em uma linguagem homogênea, e as únicas soluções dentro de tanta uniformidade eram as soluções de esquina (PATETTA, 1987). 


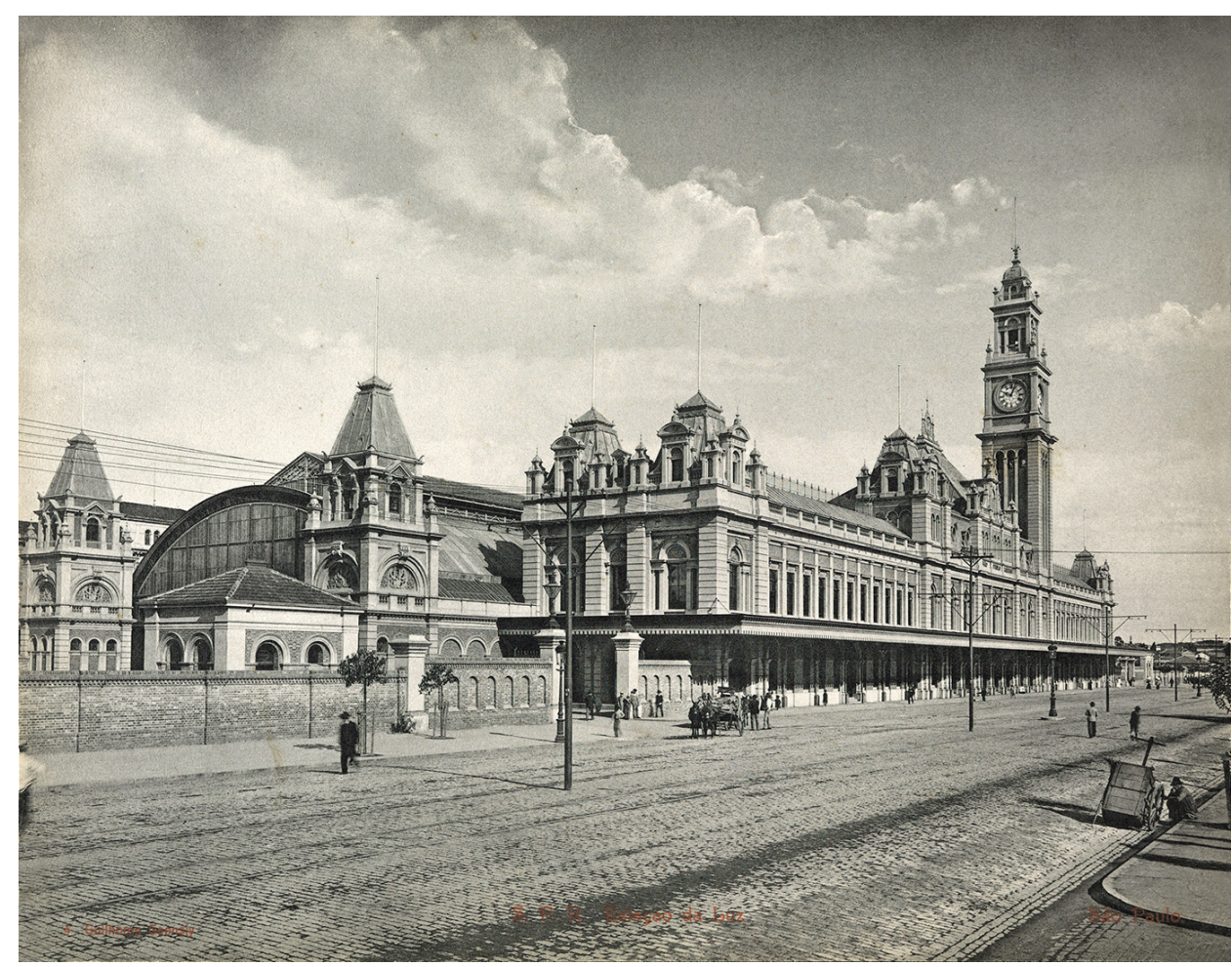

Figura 3: S. P. R. Estação da Luz. Fonte: https://bit.ly/2WV5tMt.
Ao lado dos grandes monumentos tradicionais, a arquitetura oitocentista no Brasil exibe um novo tipo de fetiche, fruto do progresso e da indústria, a estação ferroviária. Totalmente projetada em Londres, a Estação da Luz de São Paulo (figura 3) é um exemplo. Ferro e alvenaria se misturam em sua composição, aspecto funcional seguido de decoro e ornamento.

O despertar nacionalista causado pela Primeira Guerra Mundial atinge o Brasil, levando-o a repensar suas questões artísticas. Ricardo Severo toma para si a tarefa de eliminar o mau gosto presente na arquitetura nacional na conferência realizada em julho de 1914 intitulada "A arte tradicional brasileira". O estilo neocolonial se torna uma reação dominante a partir dos anos 1910. Azevedo (1920) caracteriza São Paulo como um sujeito enriquecido que quis escrever o seu passado materialmente modesto, mas honradamente honesto.

Contra o mau gosto ergue-se um modelo arquitetônico robusto, forte, de linhas calmas, que corresponde entre a arquitetura e as necessidades do século XX e o estilo "bonitinho" mistura a arte nova e gótica com marquises Luís XVI. O neocolonial se torna o último capítulo da saga eclética no Brasil, resultando em soluções de superfície inspirados em sua maioria na arquitetura portuguesa (FABRIS, 1993). 
4Exposição Internacional de Artes Decorativas e Industriais Modernas, realizada em Paris durante abril e outubro de 1925 (SUTCLIFFE, A. Paris: An Architectural History. New Haven: Yale University Press, 1993)

\section{Caminho da modernidade: Art Déco no Brasil do século XX}

Até a virada do século XIX os mestres de obras dominavam o mercado de construção, estes eram normalmente pedreiros de origem portuguesa que organizavam o interior e o exterior das residências. As fachadas eram semelhantes e estavam alinhadas a uma ideia de continuidade em ambos os lados da rua, apresentando unidade (BRUAND, 1981).

Os arquitetos em sua maioria vinham de países europeus, enquanto a minoria brasileira era formada por formandos da Escola Nacional de Belas Artes, fundada em 1981, na cidade do Rio de Janeiro. Estes profissionais se dedicavam na construção de prédios públicos e casas para uma elite dominada e entusiasmada pelo estilo eclético - neogrego, neorromano, neobarroco, neocolonial, e assim por diante (CAVALCANTI, 2006).

Ligado ao fenômeno artístico e a indústria, Figueiredo e Ramos (1980) definem o Art Déco como sendo a tentativa de unir arte e indústria na era da máquina. Segawa (1998) restringe o uso do termo no país a vertente mais ligado ao sentido decorativo do que ao sentido construtivo. Para Hillier (1940) o uso do termo Art Déco emprega a definição de um estilo moderno, desenvolvido nos anos 1920, mas que alcança seu ponto alto nos anos 1930. Um estilo clássico assim como o neoclássico, respondendo as exigências da máquina e dos novos materiais.

A Primeira Guerra Mundial tem fator decisivo na reestruturação social da arte na sociedade, com a vitória francesa, o ambiente encarnado na Exposição de $1925^{4}$ foi um compromisso inconsciente da arte decorativa, e seus ideais democráticos, com a relação com o universo industrial (BRESSLER, 1997). Nos Estados Unidos, nação que emergiu da Primeira Guerra como país credor, favorecido pelo momento econômico e desenvolvimentista, a adesão a um estilo era necessária para espelho do progresso nacional. Nesse sentindo, o Art Déco se firma como um estilo urbano, aberto e eclético, frente ao caráter idealista e moralista das vanguardas do outro lado do atlântico (FRAMPTON, 1997).

Para Reis (2014) nas primeiras décadas do Brasil do século XX, a acepção do moderno era indicada como sinônimo de atualidade, acessibilidade e fidelidade ao padrão que vigorava na Europa e Estados Unidos e, na arquitetura, o conceito estava relacionado a mais um fenômeno de modismo, intercambiável, de gosto.

Na arquitetura, o moderno, associado ao déco, foi materializado em uma gama de programas e tipologias representativos da vontade de modernizadora e progressista de uma época marcada pela emergência de uma cultura de massas e metropolização urbana (REIS, 2014, p. 45)

O surgimento do Art Déco no Brasil coincide com processo de modernidade que alavancou o país nas primeiras décadas do século XX. A popularização do estilo nas décadas de 1930 e 1940, em um cenário político instável, fez debates surgirem na sociedade ligada às artes e a cultura. A própria Semana de Arte Moderna de 1922, com seus incipientes Mário de Andrade, Menotti Del Picchia e Oswald de Andrade, exaltou os ânimos nos diferentes nichos formadores de opinião (GUIA, 1997).

O florescimento político-social deu espaço à cultura de massa e a ascensão da camada média da população e, nesse cenário, a transformação das metrópoles nas principais capitais do país eram acompanhadas do desenvolvimento econômico. Com a adesão do 
Figura 4: Viaduto do Chá de Elisário Bahiana. Fonte: <https:// bit.ly/3hqKx9p>.

Figura 5: Instituto Biológico de Mário Whately. Fonte: <http:// www.biologico.sp.gov.br/>. capital privado emergem nas cidades novos contornos, como o advento da verticalização (REIS, 2014)

No Brasil, o impacto do Art Décose deu mais a questões de afirmação de uma modernidade do que a um tipo de divisor social entre classes. Ambos os estilos foram apropriados pelas elites locais e desgarrados de significados, tanto cultural quanto temporal, pela propagação de maneira absurda deste estilo (DENIS, 2008).

Na capital paulista podemos tomar de exemplos da arquitetura Déco o Edifício Saldanha Marinho (1933) e o Viaduto do Chá (1938) - figura 4, feitos por Elisiário Bahiana, o Instituto Biológico (1928) - figura 5, de Mário Whately e as casas de Jayme Fonseca Rodrigues, na Rua Ceará (1935) - figura 6. Na capital carioca, destacam-se, Estação da Central do Brasil (1937), feita por Roberto Magno de Carvalho, o Edifício Novo Mundo (1934) de Ricardo Wriedt e o edifício Standard (REIS, 2014).
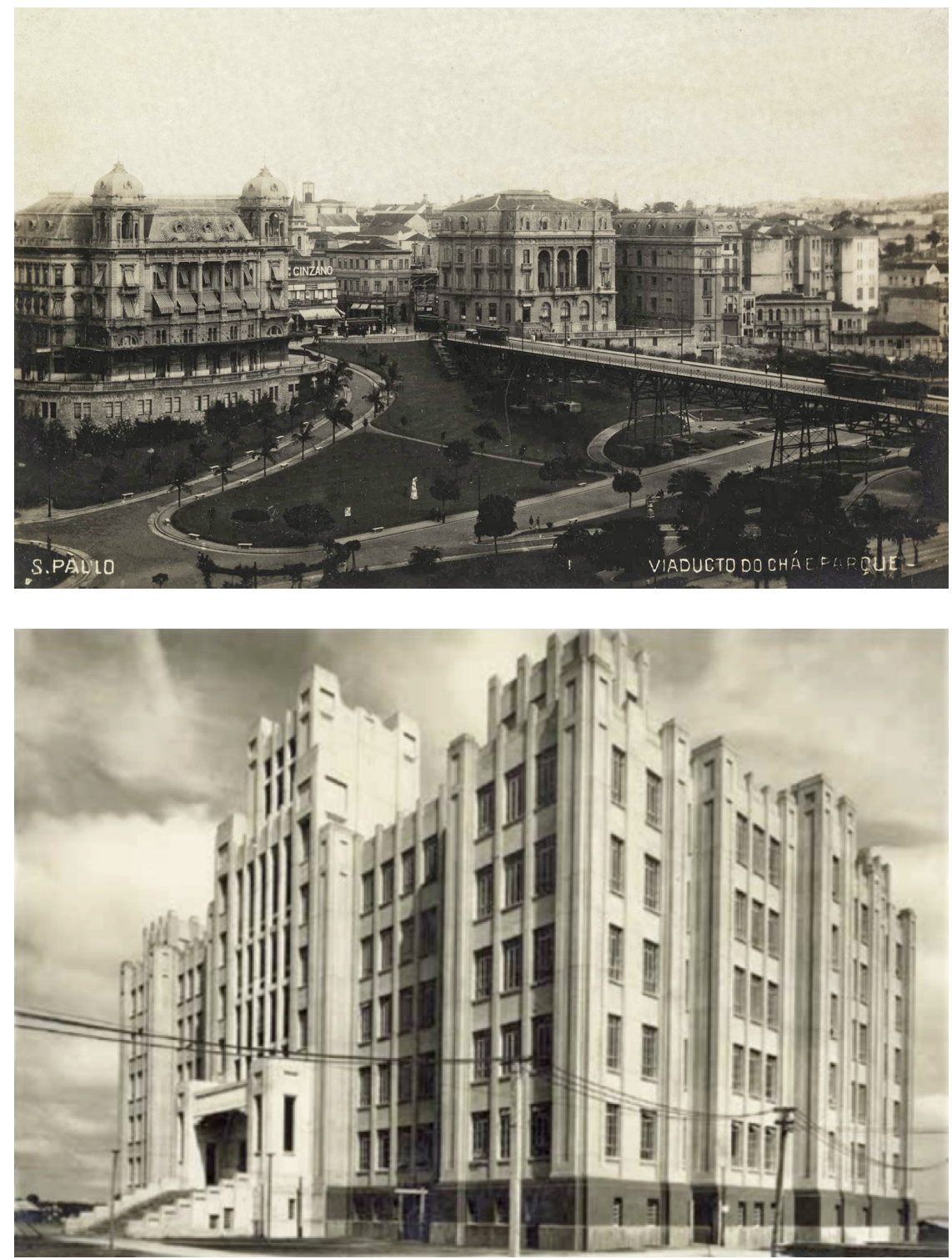
Figura 6: Casa de Jayme Fonseca Rodrigues. Fonte: <http://etad. com.br>.

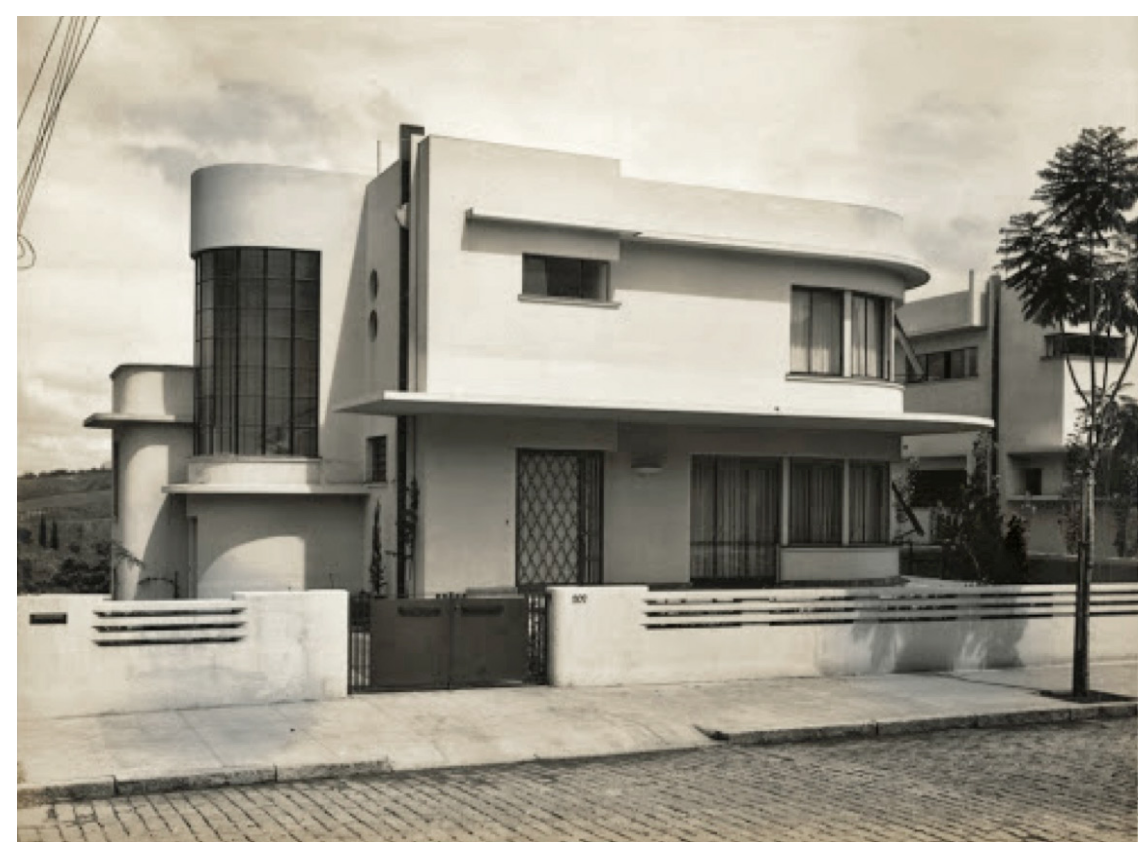

A simplificação das formas era uma estratégia do estilo Art Déco na arquitetura, o revestimento exterior de pó-de-pedra (mica) e o embasamento recoberto por granito ou outros materiais de melhor qualidade eram encontrados com frequência nos projetos. A superfície dos edifícios era predominada entre o jogo de vazio e cheio, com a sensação da construção amenizada pelas varandas (/dem, 2014).

As novas tecnologias como o concreto armado eram assimiladas pelo Art Déco, pela sua relação com o mundo industrial, "seu vínculo com a moderna tecnologia da construção dão às suas formas um sentido de modernidade, de projeção para o futuro" (SEGRE, 1991, p.111). O sentido de modernidade, exposto por Segre (1991), refere-se à racionalidade da arquitetura moderna, mas não modernista. As construções em Art Déco tomavam como pressuposto a racionalidade das formas e a geometria, o sistema construtivo estrutural e a estética própria, unindo as condições projetuais e funcionais.

Para o pintor Theodoro Braga, conhecedor da arte marajoara, os arquitetos deveriam prestar atenção a fauna e flora brasileira para se inspirar e, basear na sua construção, elementos que caracterizassem uma arte brasileira. O estilo Marajoara, inspirado nas cerâmicas dos povos indígenas da llha do Marajó, logo se tornou o Art Déco nacional, figura 7 (BRAGA, 1940).

Na Era Vargas (1930-1945) e, depois sob o comando de Juscelino Kubitscheck (19561961), o Brasil estava em seu momento de formação contemporânea. A renovação de valores e costumes estavam em vigência, o país enfrentava uma febre de modernização. Em paralelo as políticas nacionalistas adotadas, o design brasileiro e a arquitetura estiveram obrigados a propor soluções à altura dos grandes desafios sociais e culturais do período (DENIS, 2008). 
Figura 7: Edifício Itahy (RJ) "Nativismo puro: uma sereia com traços indígenas coroa a entrada do Edifício Itahy, em Copacana, no melhor estilo art déco". Fonte: https://bit.ly/3n1Fiy6.

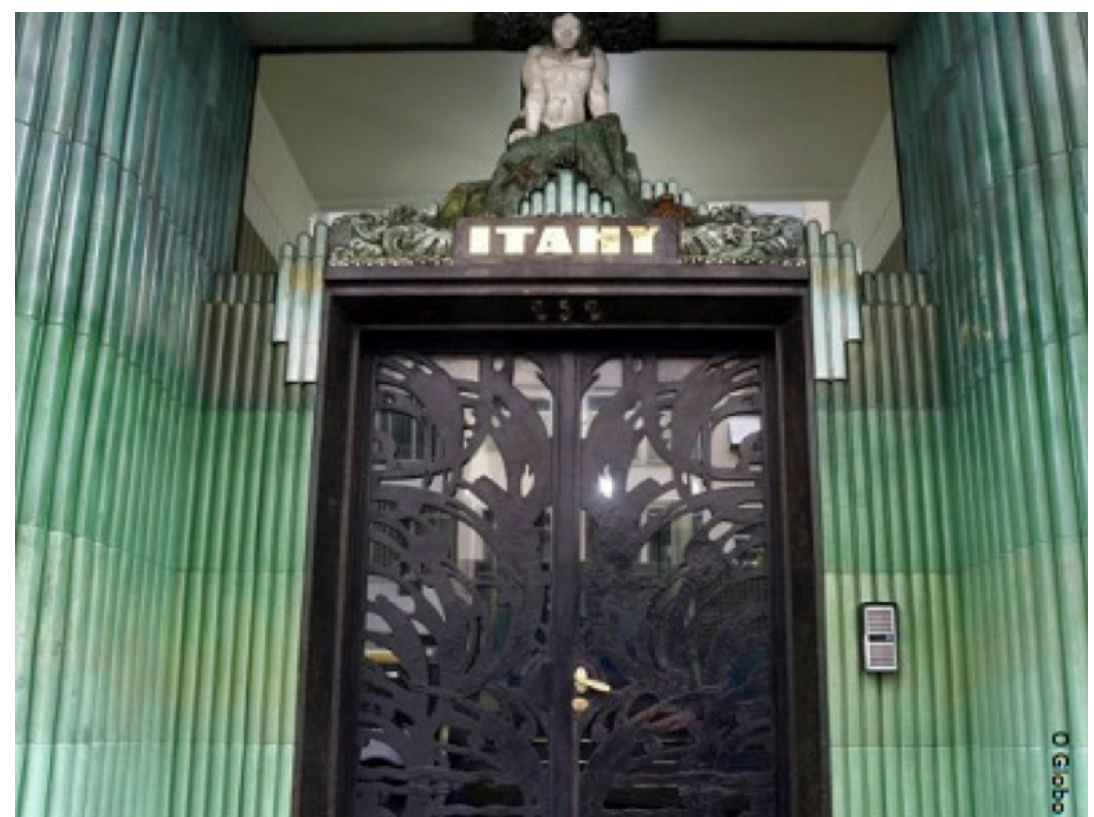

Nesse contexto, o Art Déco se desenvolve no Brasil a partir de 1925 com a divulgação mundial e, nas décadas de 1930 e 1940, se consolida como o estilo que encarnou a modernidade no país e deu acesso a uma matriz norte-americana ou europeia para as diferentes camadas sociais do território nacional.

\section{Notas conclusivas}

O Brasil não tinha uma base econômica e estrutural para as mudanças urbanas que começaram nos grandes centros, como São Paulo e Rio de Janeiro e, a partir desses marcos, diversos profissionais criaram condições para projetar, mesmo ainda que sob um padrão europeu suas primeiras intervenções na paisagem. $O$ eclético se funde na ideia de modernidade, dando um passo ao novo estilo que vigorou por um longo tempo nas projeções arquitetônicas, porém diversos fatores fazem com que esse estilo continue sendo estudado e relembrado com saudosismo pelos apreciadores da arquitetura e das formações urbanas.

Um dos fatores e, talvez o mais importante, é a relação social e política relacionada com o eclético. Como apontado pelos autores referenciados neste artigo, a questão da modernização projetual veio acompanhada de inúmeras transformações sociais, como a Revolução Industrial, marco para uma alteração de postura industrial e criativa. O impacto de tal Revolução fez com que a qualidade dos produtos se transformasse e, sobretudo se ampliasse. A ampliação do mercado consumidor, o uso de novos materiais e a adesão, mesma que sem intenção, pelo gosto alheio proporcionou uma atenção maior às práticas de projeto e sua qualidade estética no sentido do olhar atento aos diferentes acabamentos e técnicas criativas que poderiam estar nas residências. Outro fator foi o desenvolvimento da mídia impressa, a veiculação de panfletos, jornais, catálogos, etc., que fez do século XIX um centro de comércio cada vez mais acessível através do acesso da população às melhores condições. 
A elite foi o grande público-alvo das manifestações ecléticas iniciantes, o que fez com que o estilo fosse amplamente divulgado foi à adesão das classes ricas a essa modernização conjuntural e estética. Embora ressaltado neste trabalho, o ecletismo não foi um estilo unicamente de elite, pois ao longo de seu amadurecimento enquanto técnica, outras camadas da população tiveram acesso a tal prática. Mas os burgueses industriais, influenciados pelos modismos e, pelas informações veiculadas pela imprensa, encarnaram no eclético seu estilo de prosperidade.

No Brasil o ecletismo foi um forte estilo arquitetônico e cultural, suas obras resistem até os dias de hoje e são marcos icônicos de diversas cidades do país, das capitais ao interior. Cabe aos pesquisadores e estudiosos destas áreas corrigir o julgamento sobre a cultura eclética e ressaltar as contribuições que constituem, ainda hoje, um patrimônio tão precioso. Foi graças ao eclético e, posteriormente ao Déco, que o Brasil construiu sua identidade através da linguagem arquitetônica.

Apesar do contexto de absorção cultural de influências externas, o Brasil conseguiu superar a barreira e buscou a reinterpretação de seus códigos, no campo artístico em geral, ainda que através de pequenas alterações no cotidiano, como objetos, têxteis, cerâmicas, mobiliário, o estilo se afirmou e ganhou novas encomendas.

Em um país marcado pela colonização em diversos momentos, por tantas intervenções culturais e políticas externas, por meio da miscigenação entre povos do mundo todo, a arquitetura brasileira não poderia refletir diferente. A arquitetura brasileira é resultado de sua história e sua história é profundamente eclética.

\section{Agradecimentos}

O presente trabalho foi realizado com apoio da Coordenação de Aperfeiçoamento de Pessoal de Nível Superior - Brasil (CAPES) - Código de Financiamento 001.

\section{Referências bibliográficas}

ARGAN, G. C. II revival. In: I/ revival, Milano: Mazzotta, 1974.

AZEVEDO, V. de Paula Vicente de. A pirâmide do Piques. Revista do Brasil, São Paulo, n 54 , jun. 1920 .

BONAMETTI, João Henrique. A Arquitetura Eclética e a Modernização da Paisagem Urbana Brasileira. Revista Cientifica/FAP, [S.I.], dez. 2007. ISSN 1980-5071. Disponível em: <http:// periodicos.unespar.edu.br/index.php/revistacientifica/article/view/1741>. Acesso em: 10 Out. 2019.

BRAGA, Theodoro. Por uma arte brasileira. Acrópole, ano 2, n. 20-21, p. 25-26, dez-jan. 1940.

BRESSLER, Henri. O Art Décoratif Moderno na França. In: Art déco na América Latina. Centro de Arquitetura e Urbanismo do Rio de Janeiro - $1^{\circ}$ Seminário Internacional. Rio de Janeiro: Prefeitura da Cidade do Rio de Janeiro/SMU, Solar Grandjean de Mon-tigny - PUC/RJ, 1997.

BRUAND, Y. Arquitetura Contemporânea no Brasil. São Paulo: Perspectiva, 1981.

DENIS, Rafael Cardoso. Uma Introdução à História do Design. São Paulo: Editora Blucher, 2008.

CAVALCANTI, Lauro Pereira. Moderno e brasileiro: a história de uma nova linguagem na arquitetura. Rio de Janeiro: Jorge Zahar, 2006 
EAGLETON, Terry. A ideologia da estética. Rio de Janeiro: Zahar, 1993.

FABRIS. Annateresa. Arquitetura eclética no Brasil: o cenário da modernização. Anais do Museu Paulista: História e Cultura Material, v. 1, n. 1, p. 131-143, 1 jan. 1993.

FIGUEIREDO, Luciano; RAMOS, Oscar. RIO DECO. Rio de Janeiro: Edições Achiamé, 1980.

FRAMPTON, Kenneth. Arquitetura e Estado: ideologia e representação, 1914-43. In: História crítica da arquitetura moderna. São Paulo: Martins Fontes, 1997.

GUIA da arquitetura art déco no Rio de Janeiro / Prefeitura da Cidade do Rio de Janeiro, Secretaria Municipal de Urbanismo. Rio de Janeiro: Index, 1977.

HILLER, Bevis. Art Deco of the 20s and 30s. Londres: Studio Visa, 1968.

LEME, Silvia. Urbanismo no Brasil. São Paulo: FUPAM/USP, 1999.

MIGNOT, C. L 'architecture au XIX siecle. Fribourg: Office du Livre, 1983.

MORAES, José Geraldo V. de. Cidade e Cultura urbana na primeira república. São Paulo: Atual, 1998.

PATETTA, Luciano. Considerações sobre o ecletismo na Europa. In: FABRIS, Annateresa. Ecletismo na arquitetura brasileira. São Paulo: Nobel, 1987.

PEVSNER, N. Génie de L'architecture européenne. Paris: Le Livre de Poche, v.2.,1970.

QUEIROZ, M.I. Pereira de. Ainda uma definição do 'ser brasileiro'?. In: RODRIGUES, L. Martins (org.). Trabalho e cultura no Brasil. Recife, ANPPCS/ Brasília, CNPQ. 1981.

REIS, Márcio Vinicius. O art déco na Obra Getuliana. Moderno antes do modernismo. Tese (Doutorado em Arquitetura e Urbanismo - FAU/USP). São Paulo, 2014.

SALGUEIRO, H. Angotti. L'influence de I'architecture française du XIX siecle au Brésil: le cas de Belo Horizonte. Montpellier: Université Paul Valéry, 1986.

SEWAGA, Hugo. Modernidade Pragmática 1922-1943. In: Arquiteturas no Brasil 19001990. São Paulo: Edusp, 1998.

SEGRE, Roberto. América latina, fim de milênio: raízes e perspectivas de sua arquitetura. São Paulo: Nobel, 1991. 